\title{
THE END OF INTERDISCIPLINARY RESEARCH
}

\author{
Richard L. Schowen \\ Departments of Chemistry, Molecular Biosciences, \\ and Pharmaceutical Chemistry \\ Higuchi Biosciences Center, University of Kansas
}

\section{Introduction}

The call for interdisciplinary research efforts is one of the very small number of truly interdisciplinary phenomena in American universities today. For example, the awe that attends the pronunciation of the term interdisciplinary is equally profound among practitioners of the "hard sciences" and among scholars in gender and ethnic studies. Otherwise these camps share only the most devout suspicion of the methods, motives, and general probity of the other camp. Yet without detectable exception, both groups and all those between and on orthogonal axes, including such mixed exotica as engineers, pharmacists, journalists, and belle-lettrists, offer limitless devotion at the altar of the interdisciplinary. ${ }^{1}$

This circumstance is surely odd. For a simple, minimal definition of interdisciplinary is "having no coherent relationship to the normal scholarly organization of universities." Yet we see university scholars one and all calling for the pursuit of research by a method the defining characteristic of which is a radical mismatch to the organization of scholarship within which all of these scholars were educated, within which they are educating their students, and-as we shall see-to which they can manifest the fiercest of loyalties. I should like to address this conundrum after a necessary pause for clarification.

\section{Terminological Interlude}

There seem to be three common terms abroad in discussions of research that fails to align itself within established disciplinary lines: multidisciplinary, interdisciplinary, and cross-disciplinary. For purposes of this article, I would like to adopt definitions of these terms that follow from but do not correspond precisely to the usages reviewed and advocated by Epton, Payne, and Pearson (1983, pp. 1-9). These definitions should be useful but do not play any large role in the considerations addressed here:

multidisciplinary: the research is executed independently by specialists working in their own disciplines, and the multidisciplinary product of the research is obtained by integration of their finished results.

interdisciplinary: the research is conducted by a team of investigators from different disciplines, working together and bringing their disciplinary skills and information to bear on the investigation at the most primitive level. 
cross-disciplinary: a particular task within a research project calls upon specialists in different disciplines each to contribute collaboratively to completion of the task by bringing their specialized capacities to bear.

These definitions are illustrated in Figure 1, which portrays various aspects of the research, development, and technology transfer activities associated with a most demanding project, four-alarm sushi.

\begin{tabular}{|c|}
\hline Four-Alarm Sushi \\
Multidisciplinary: \\
Mexican cook makes salsa; \\
Japanese cook makes sushi; \\
Combination: four-alarm sushi \\
Interdisciplinary: \\
Japanese cook and Mexican cook \\
get rice, peppers, tuna, tomatoes, \\
seaweed, etc., drink a case of beer \\
and end up with four-alarm sushi \\
Cross-disciplinary: \\
Marketing of four-alarm sushi \\
requires collaboration of lawyers \\
who know raw-fish products with \\
lawyers who know multi-alarm \\
products.
\end{tabular}

Figure 1. Research and development modalities in the field of four-alarm sushi. In a multidisciplinary approach, the independent products of disciplinary specialists are integrated. In an interdisciplinary approach, specialists cooperate at a primitive level. Cross-disciplinary task completion is illustrated by legal problems in the marketing of four-alarm sushi, which is expected to pose monumental challenges.

In the present article, we restrict our attention to the interdisciplinary modality, which carries the challenge to traditional academic organizational schemes to the most troubling level.

\section{The Disciplinary Conundrum}

The necessity of interdisciplinary research arises from the level of difficulty of the research problems currently under attack. In all fields, the easy work is finished and ambitious scholars are confronted with problems that perniciously defy easy categorization in the traditional disciplinary format. Chemists can no longer find a significant research subject that is purely chemical in nature. Instead, they are forced by the problems they wish to solve to consider information and to apply skills that traditionally derive from physics, biology, engineering or more distant areas. 
It is an intrinsic feature of this argument that scholarly disciplinary lines have not shifted to accommodate the shifts in information and skills that are demanded for the solution of current research problems. In fact, taking the organization of the "hard sciences" as an example, the disciplinary lines of biology, chemistry, and physics (deriving in the case of biology and physics from ancient Greek philosophy) began to emerge in their present form in European and American universities during the Romantic Era of the 19th century. Much of the difficulty that university scholars experience in laying aside their disciplinary loyalties for research purposes comes out of emotional traditions that reflect the atmosphere of Romanticism in its fullest flower.

\section{Romanticism and Scientific Disciplines}

The project of the Romantics, beginning in the 1790s, "after the rationalism and decorum of the Enlightenment" to "save the overview of human history and destiny, the experiential paradigms and the cardinal values of their religious heritage," in part through "a reversion to the stark drama and suprarational mysteries of the Christian religion" was not without influence among natural scientists (quotations from Abrams, p. 66). The co-evolution of Romanticism and the developing organization of the subdisciplines of chemistry is illustrated in Figure 2.

The great figure of 19th-century German chemistry, Wilhelm Ostwald, recognized so clearly the role of Romantic thinking not only in the organization but also in the conduct of science that he divided scientists into "Classicists" and "Romantics." The Romantics, declared Ostwald, show the following characteristics (Rodnyj \& Solowjew, 1977):

- They work fast and move rapidly from problem to problem.

- They tend to be the founders of great schools of disciples (Ostwald cited Liebig, with pupils and influence reaching beyond Germany to England, Russia and the USA).

- They become not only active combatants but also passionate propagandists for their ideas and viewpoints.

- They favor broad and multifaceted problems but must defer to the Classicists in matters of depth and fundamental significance.

It is not hard to detect here in a scientific context the dark side of the Romantic character, in which "suprarational mysteries" tended toward extreme tribalism, racism, nationalism, and jingoism, with the catastrophic sequelae described in part by Mosse (1964). Such irrational emotional devotion has not been absent from the disciplines of scientific organization. Every scientist will recognize the incompletely jocular strain of fierce loyalty expressed in the Fest-Cantus ${ }^{2}$ John Read sang with his fellow students at the University of Zurich during their Christmas party in 1906 (Read, 1947, p. 277): 
Then shout with voices in alliance:

"Prosperity and growth to Science!"

And cry with all your energy:

"Long life to Chemistry!"

\section{A Subdisciplinary Chronology}

Annales de chimie et de physique

Journal of the Chemical Society

Z. für analytische Chemie

Z. für physiologische Chemie

1877

Z. für physikalische Chemie

Z. f. anorganische $u$. allgem. $\mathrm{Ch}$.

1892

Journal of Organic Chemistry

1935

Biochemistry

1961

Figure 2. Development of the chemical subdisciplines, as reflected in the foundation of subdisciplinary journals, during the Romantic Era (data in part from Neufeld, 1977). Lavoisier's journal, the Annales, published both chemistry and physics at the time of the French Revolution, but by 1841 the Journal of the Chemical Society was concentrating on chemistry alone. The German chemical press $(Z .=$ Zeitschrift; allgem. = allgemeine) began the fragmentation into the occasionally warring tribes of analytical, physiological, physical, and inorganic chemistry. The apparently late foundation of the Journal of Organic Chemistry in the USA is merely indicative of the domination of organic-chemical papers in the general chemical journals throughout most of chemical history, while Biochemistry simply re-names physiological chemistry.

The powerful loyalties that attach to the scientific disciplines and their individual subdisciplines are thus of at least a partially irrational origin (some rational contributions will be considered below). Such loyalties, seemingly inexplicable but freighted with a heavy emotional weight, may thus explain the unusual survival properties of those hardy perennials, our scientific disciplines, that have kept them flourishing so long in the university hothouse.

In fact, the disciplines have flourished in the very face of attack by their own research objects. The shapes of research challenges in both fundamental and applied science, and in all the shades of overlap between, have stubbornly declined formulation along disciplinary boundaries. 
Thus we have the strange phenomenon of interdisciplinary research. It is fundamentally occasioned by our unwillingness or inability, as university scholars, to give up the traditional modes of scholarly organization and to adopt instead more modern and flexible alignments that have more coherence with respect to research demands.

\section{The End of Interdisciplinary Research: the Elimination of the Scientific Disciplines?}

To the extent the highly doubtful foregoing analysis has any validity, the appropriate course of action for mobilizing the sciences for research opportunities in the next century would appear to be simple and clear.

For maximum flexibility and effectiveness in addressing new research opportunities, the scientific disciplines, which are emotion-laden and archaic remnants of Romantic irrationality, should be eliminated.

Is this in fact a project that is either possible or desirable? Some facts suggest that the elimination of scientific disciplines from the fabric of university organization is neither possible nor, if it were possible, desirable. These facts are:

- Traditional scholarly alignments provide a valuable engine for the nurturing and validation of expertise that we cannot do without.

Every discipline provides its practitioners with skills that are vital for research success in interdisciplinary research. For example, problems of molecular structure determination call upon chemical skills and the solution of such problems in the interdisciplinary context commonly presupposes the availability of a chemically trained practitioner. Similarly, cell culture problems are most likely to be successfully addressed by persons trained in biology, etc.

In fact, the traditional disciplines and subdisciplines within them have evolved an informal but enormously functional and efficient scheme of division of labor so that expertise is produced and validated in a reliable manner. ${ }^{3}$ As we cannot readily dispense with expertise, we cannot dispense with scientific disciplines without an address to this problem.

Furthermore, the overall validation of educational and research functions within the traditional disciplines is often provided by professional organizations for which no analog has been invented to take their place in the imagined post-disciplinary world.

- Education in the physical and biological sciences, as it is currently constructed, depends upon a specific model of the disciplinary division of labor, the "vertical" model described by Westheimer. ${ }^{4}$ 
According to the "vertical" model, a future biologist cannot be launched on the serious study of biology without first acquiring a sufficient basis in chemistry to understand the molecular basis of biology. In turn, the student cannot acquire this chemical basis without a grounding in physics, which further presupposes command of a certain amount of mathematics. In the American academic world, this entire process of acquisition proceeds within the university disciplinary context, none of the requisite information or skills being presupposed upon arrival in the university. The scheme works well but predicates the existence of academic departments in these traditional areas. In our imagined post-disciplinary paradise, we have yet to describe the solution of the educational problem posed by the disappearance of the disciplines.

Thus a number of reasons can be advanced that suggest the elimination of the traditional disciplines is not the facile project one might have imagined.

This is not to say that changes in disciplinary organization, if not the actual elimination of disciplinary boundaries, are unknown. Indeed, the ethnic and gender studies departments referred to at the beginning of this article commonly are composed of scholars whose own doctoral degrees are likely to have been obtained in more traditional fields. On the technical side, environmentally oriented departments have frequently been assembled, with a corresponding composition of members with training in specific, traditional disciplines.

Not uncommonly members of such novel departments hold simultaneous appointments in departments that call upon their traditional loyalties. This fact might be interpreted as indicating a type of missionary activity at work, with the traditional metropolitan disciplines loosing their more adventurous populations into the interdisciplinary jungles. Alternatively, it might be thought that a well-founded consideration of the probable eventual fate of non-traditional departments in universities gives reason for their inhabitants to develop and maintain, along with their holdings in the colonial enterprise, a purchase on some higher and drier ground.

Changes in disciplinary organization even within the "hard sciences" can occur. My own university affiliation is in part (perhaps the other parts represent higher and drier ground) to a department currently in the process of incorporating members from the traditional areas of Biochemistry, Cell Biology, Physiology, and Microbiology. The amalgam will probably be known as "Molecular Biosciences," a name that displays not only the wit of brevity but also the generous rationality of its members.

Even when changes in disciplinary alignments do occur, however, the wily mutability of research problems tends to outrun the pace of realignment, and the call for interdisciplinary cooperation continues. Thus the question:

Short of the elimination of the disciplines, how can an effective and flexible response to research challenges be mounted, i.e., what are the factors that favor interdisciplinary research? 


\section{Waiting for the End of Days: Nurturing Interdisciplinary Research}

I would like to call upon three decades of participation in interdisciplinary scientific work at the University of Kansas to identify some of the features that have made the activity functional and facile at that institution. I deliberately concentrate on features that ought to hold equally well in any institution, and I omit personal qualities of the investigators. I claim these two items to be most important:

\section{- The presence of supraterritorial research centers.}

Much of my own work has played out in the Higuchi Biosciences Center, its component centers, and its predecessors. The telling quality of these centers has been that they lie beyond the normal territorial organization of the university. Their responsibility is not to the dean of any school or college, nor to the chair of any department, but rather to the university research enterprise and-in effect-to the faculty at large. This feature allows projects to be attacked readily by crews of investigators from any combination of entities in the university. At the same time, the question is largely skirted of how to make a territorial assignment of grant income, credit for publications, and the other vital signs by which universities measure the health of their internal organs.

I hasten to add that I do not claim that the chief value of the supraterritorial feature is that it avoids the feral territorial instincts or Romantic irrationality inherent in the make-up of department chairs or college deans (here I can be seen climbing rapidly to higher and drier ground). In fact, what the research enterprise is exempted from is the rationality and sense of responsibility that are typical of chairs and deans (quite high, quite dry). At Kansas and indeed at most research universities, chairs and deans are frequently afflicted by critical unmet needs with large, strong constituencies and very short time-lines. The supraterritoriality of research centers removes the research enterprises within them from being balanced against such demands. When it is considered that in interdisciplinary work, a number of chairs and deans must simultaneously be involved, the supraterritorial quality becomes vitally significant.

\section{- The absence of sharp accounting practices.}

I have already referred to the conflicts with effective interdisciplinary work set up by questions of how grant income and publications, for example, will be allocated among the organizational home territories of the participating researchers. Such problems can readily be elevated to the fatal level by internal accounting practices that insist on making a zero-sum game of such divisions. Then every collaboration across disciplinary lines tends to be preceded by a series of acrimonious negotiations the bitterness of which is described by Kissinger's Dictum. ${ }^{5}$ The merciful absence (to date) of such practices at the University of Kansas has made it an institution very friendly to interdisciplinary research. In institutions where the critical accounting decisions on this point have not been made (surely few indeed), it may be worthwhile 
to be alert to the Algorithm Problem. At some point, research-management software is written in which is embedded an algorithm that allocates grant income and other productivity measures among university entities. Once the software is implemented, changes become impossible so it is vital to raise the alarm in advance. Otherwise, the critical decision is made at 3 a.m. by a teen-age computer-science student, her nervous system jangling with caffeine, who has been hired as a minimum-wage programmer. The decision thus made then has a serious determining effect on the research future of the institution: if the accounting is generous and clever and does not create a zero-sum game, the future is bright. Otherwise, dismal.

\section{Summa}

Interdisciplinary research will end, when and if university faculties can abandon the traditional lines of scholarly organization. Factors that are of the utmost irrationality and of the utmost rationality suggest that the third millennium may be an early date for this occurrence. Before then, measures that depress the roles of territorial feeling and territorial reasoning (while preserving the benefits we derive from our much-loved disciplines) should advance the cause of institutional flexibility in meeting research challenges. 


\section{Acknowledgments}

In addition to the debts to which I have confessed in the text and footnotes, the bibliography lists a number of other sources of relevant information.

\section{Endnotes}

(1) An appropriate recipient of these devotions would be the deity Hermaphroditus. Robert Graves (The Greek Myths, Penguin, London, 1960, vol. 1, p 68) notes that the mother of this interdisciplinary being succumbed amorously to its father after the latter had witnessed her trapped by her husband in dalliance with still another man. This is the requisite attitude for interdisciplinary work.

(2) The translation is Read's, from the original:

D'rum ruft mit voller Lungenkraft:

"Es lebe hoch die Wissenschaft!"

Und schreit mit aller Energie:

"Hoch lebe die Chemie!"

The scansion is thus unimproved in the German.

(3) I am much indebted for this insight to Professor Daryle Busch of the Department of Chemistry, University of Kansas, during our occasional discussions of the value or lack thereof of subdisciplinary divisions in the discipline of chemistry.

(4) Professor Frank Westheimer of the Department of Chemistry and Chemical Biology at Harvard University has made this point eloquently: Westheimer, F.H. (1994) Deciding how much science is enough, Journal of College Science Teaching, 23, 203-204.

(5) "Academic politics is so bitter because the stakes are so small." Attributed to the one-time American Secretary of State and long-time academic Henry Kissinger. 


\section{Bibliography}

Abrams, M.H. (1971) Natural Supernaturalism: Tradition and Revolution in Romantic Literature, W.W. Norton \& Co., New York. York.

Allison, P.D. (1980) Processes of Stratification in Science, Arno Press, New

Chubin, D.E., Porter, A.L., Rossini, F.A., Connolly, T., Eds. (1986) Interdisciplinary Analysis and Research: Theory and Practice of Problem-Focused Research and Development, Lomond Publications, Mt. Airy, MD.

Epton, S.R., Payne, R.L., Pearson, A.W., Eds. (1983) Managing Interdisciplinary Research, John Wiley \& Sons, Chichester. York.

Ihde, A.J. (1964) The Development of Modern Chemistry, Harper \& Row, New

Kargon, R.H., Ed. (1974) The Maturing of American Science, AAAS, Washington.

Mayr, E. (1982) The Growth of Biological Thought: Diversity, Evolution and Inheritance, Harvard University Press, Cambridge.

Mosse, G.L. (1964) The Crisis of German Ideology: Intellectual Origins of the Third Reich, Grosset \& Dunlap, New York.

Neufeld, S. (1977) Chronologie Chemie 1800-1970, Verlag Chemie, Weinehim.

Read, J. (1947) Humour and Humanism in Chemistry, G. Bell \& Sons, London.

Rodnyj, N.I., Solowjew, Yu. I. (1977) Wilhelm Ostwald (translated from the Russian by H. Sommer), BSB B.G. Tuebner Verlagsges., Leipzig.

Servos, J.W. (1990) Physical Chemistry from Ostwald to Pauling: the Making of a Science in America, Princeton University Press, Princeton. 